\title{
A Phase-microscopy Study of Free Cells Occurring in the Coelomic Fluid of Newts, Triturus pyrrhogaster ${ }^{1}$
}

\author{
Masahiro Mizutani and Hiroshi Nakahara ${ }^{2}$ \\ Zoological Institute, Faculty of Science, Hokkaido University, Sapporo, Japan \\ Received September 5, 1960
}

Recently, observations by phase-contrast microscopy have been adopted as a principal means to determine the morphological characteristics, dynamic behavior, distribution properties and possible functions of cellular elements in cells from the body fluid, blood or peritoneal fluid of various animals (Rizki 1953, 1957, Dalton and Felix 1955, Jones 1956, Mizutani 1958, Boolootian and Giese 1958 and some others).

Coelomic fluid of newts, Triturus pyrrhogaster, contains free cells of remarkable type having coarsely acidophile inclusions, together with histiocytes, leucocytes and lymphocytes. Ohuye (1936) who undertook morphological and cytological studies of such elements reached the conclusion that they were cells containing Russell's bodies.

The present paper deals with a phase-contrast study of the free cells, especially elements with Russell's bodies, native to the coelomic fluid of newts, with particular regard to their dynamic behavior in relation to mitotic division.

The authors wish to express their gratitude to Professor Sajiro Makino for his valuable advice and for going through this manuscript.

\section{Material and methods}

The major part of materials for this study was obtained from newts, Triturus pyrrhogaster, one of the common uroderan amphibians in the mainland of Japan, which had been stocked in our laboratory. Some wild newts collected in the suburbs of Kobe provided additional material. The free cells occurring in the coelomic fluid were obtained simply by puncturing the peritoneum with a fine glass pipett. The observations of living cells were carried out by the hanging drop method in combination with liquid paraffin according to Makino and Nakahara $(1953,1955)$ at room temperature ranging from 20 to $25^{\circ} \mathrm{C}$. The major observations were done with fresh preparations made as above with the aid of a phase-contrast microscope (Olympus

1 Contribution No. 482 from the Zoological Institute, Faculty of Science, Hokkaido University, Sappro, Japan. Supported by a Grant in Aid to Dr. Sajiro Makino from the Rockefeller Foundation for research in cytology.

2 Present address: National Pearl Research Laboratory, Kashikojima, Shimagun, Mie, Japan. 
and Tiyoda), using dark-medium contrast objectives, $40 \times$ and $100 \times$, or bright-medium contrast objectives, $40 \times$ and $90 \times$, and a Leitz Periplan $10 \times$ ocular. Smear preparations which were fixed with 10 percent acetic acid and colored with Giemsa were useful to classify free cells. In order to check the chromosome number, the water pretreatment acetic dahlia squash method (Makino 1957) was adopted.

\section{Results}

1. Morphology of free cells. Cells with Russell's bodies are remarkably large in size in the free cell population occurring in the coelomic cavity of newts. They are usually distinguishable from other types of free cells by a bipolar filamentous protoplasmic process and particular cytoplasmic inclusions. The filamentous process is hyaline in nature, and long and branched, or sometimes non-branched. The process is invisible in smears, while observable only in fresh specimens by means of a phase-contrast microscope. Occasionally, there are cells with Russell's bodies having a unipolar process
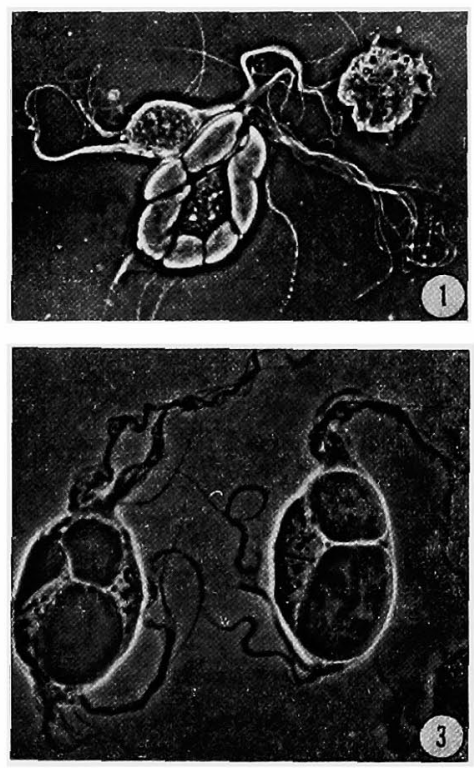
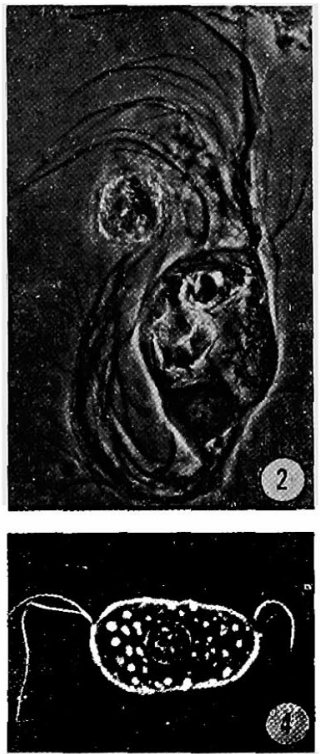
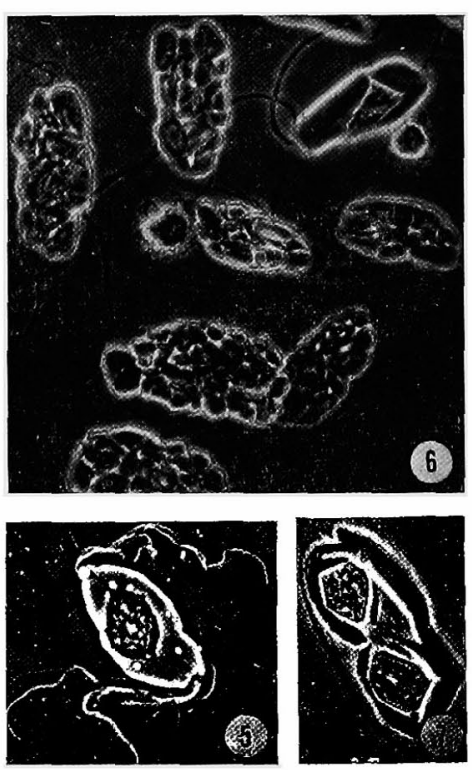

Figs. 1-7. Photomicrographs of various type of cells with Russell's bodies, taken with phasecontrast microscope. 1 , a cell at upper left has small cytoplasmic inclusions (Type 1) and a cell in the center shows several coarse inclusion bodies (Type 4). $\times 300$, bright-medium. 2 , a cell containing various kinds of crystals in a large vacuole (Type 2 ). $\times 250$, dark-medium. 3 , two cells having two and three vacuoles, respectively. A cell at right contains granules in vacuoles (Type 2). $\times 300$, dark-medium. 4, a cell showing many granules in a vacuole (Type 2). $\times 300$, bright-medium. 5, the whole cytoplasm of a cell is occupied with a large U-shaped inclusion body. Probably, it is a kind of vacuole which is filled with numerous granules (Type 3 ). $\times 250$, bright-medium. 6, most cells contain many and irregular-shaped granules (Type 4). A cell at upper right show a few solid-like inclusion bodies (Type 4). $\times 300$, dark-medium. 7 , a cell fixed with $10 \%$ acetic acid. Cytoplasmic inclusion bodies of filamentous nature seems to be rigid. $\times 300$, dark-medium. 
or no bipolar process or many short protoplasmic processes. As a rule, the nuclei are round in outline, and usually one or two in number, though three nuclei are observed rarely. The cytoplasmic inclusions are generally characterized by coarse and spherical or polygonal bodies with a high reflection. In some cases, the cells contain a large vacuole (vacuoles) in which occur acidophilic granules and crystals, needle-like, rod, diamond-shape or polyhedral in form. These cytoplasmic inclusions are those which were designated as Russell's bodies (Figs. 1-7). On this feature the names of the cells are based. Sometimes, the crystals were lost from vision by over-illumination.

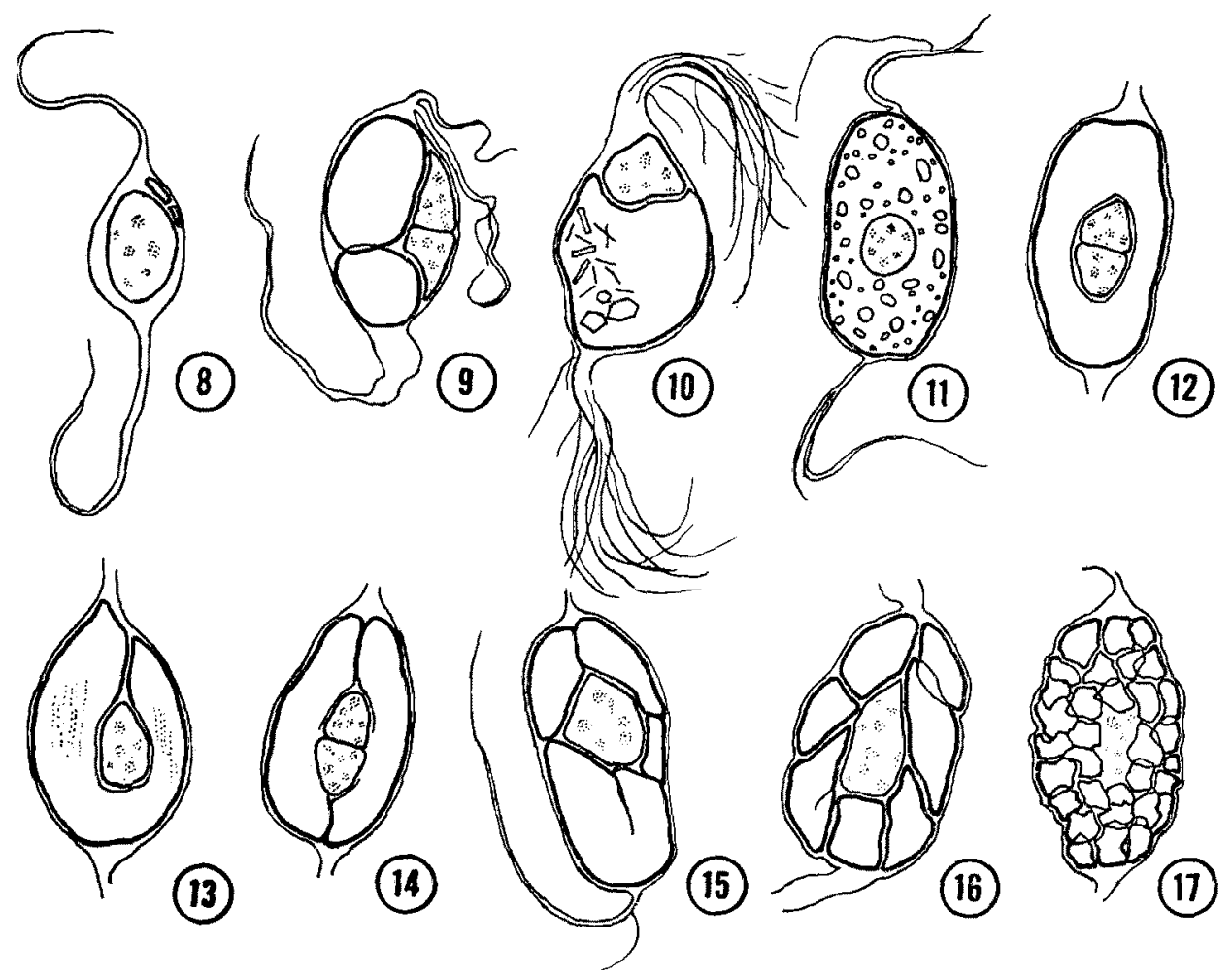

Figs. 8-17. Schematic drawings illustrating four types of cells with Russell's bodies. 8, Type 1. 9-11, Type 2. 12-14, Type 3. 15-17, Type 4.

Due to the growth of the cytoplasmic inclusions and vacuoles, the nucleus is found lying at the periphery of the cytoplasm or between the inclusion bodies, with flat, fusiform or polygonal outline. Russell's bodies seem to change their nature from basophile to eosinophile with the age of newts.

On the basis of morphological difference in the cytoplasmic inclusions, cells with Russell's bodies are roughly classified into the following four types: Type 1 refers to cells of the smallest size. Their cytoplasmic inclusions are few and small. The cells of this type are rare in occurrence in the coelomic fluid of adult newts (Figs. 1 and 8). Type 2 includes the cells which possess 
one or two large vacuoles (Figs. 3 and 9) in which crystals or acidophilic granules of various shapes are found in some cells (Figs. 2, 3, 4, 10 and 11). Type 3 comprises the cells in which ring- or U-shaped inclusions of high reflection are found (Figs. 5, 12,13,14 and 22). In some cases, the inclusion bodies appear as filamentous in structure (Fig. 7). According to Ohuye (1936), the large inclusion bodies are a kind of vacuole filled with numerous minute granules that look like solid particles. In Type 4 are included the cells showing inclusion bodies consisting of coarse and irregular parts (Figs. $1,6,15$ and 16). In some cases, cells are found with an outline like an alveolar sac (Figs. 6 and 17). The cells of this type may occur in newts of old age.
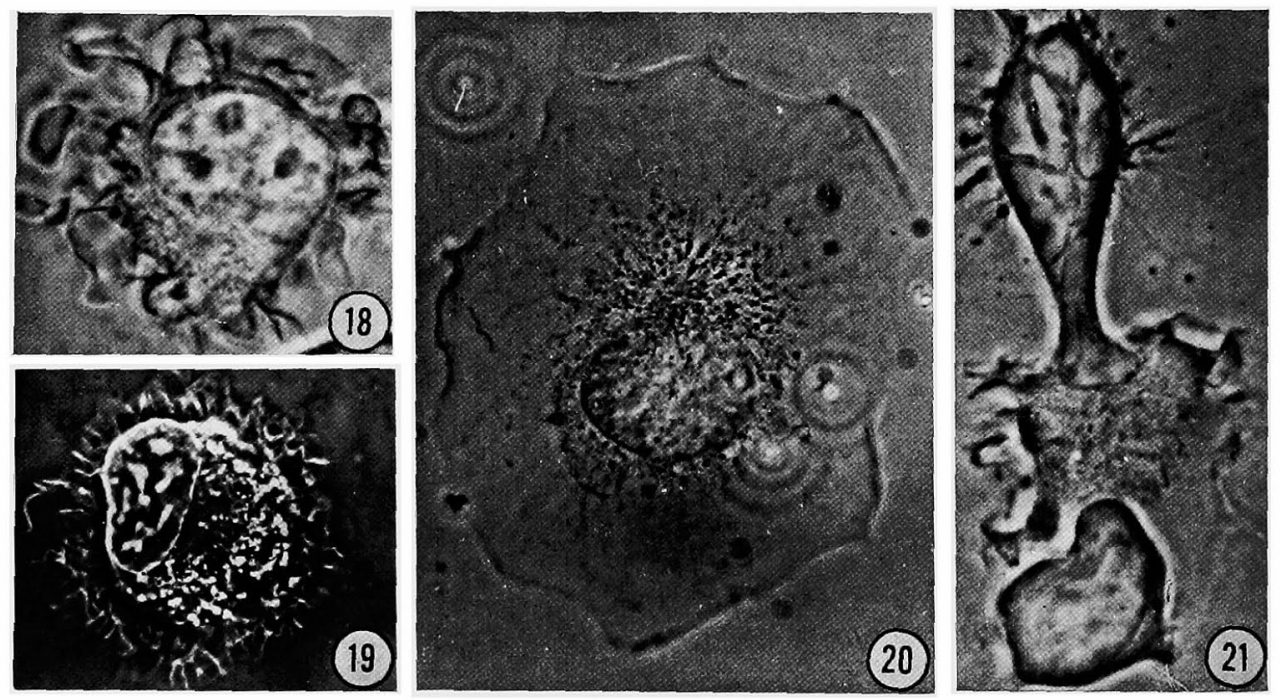

Figs. 18-21. Photomicrographs of free cells occurring in the coelomic fluid of newts, taken by phase-contrast microscopy. 18 , a histiocyte, immediately after preparation. $\times 800$, darkmedium. 19 , a histiocyte, 5 minutes after preparation. $\times 800$, bright-medium. 20 , a histiocyte, 50 minutes after preparation. $\times 800$, dark-medium. 21 , an upper cell is a neutrophilic leucocyte and a lower one is lymphocyte. $\times 800$, dark-medium.

The dominant type of cells differs not only between the newts of the laboratory stock and those from field, but also between any two individual specimens. Cells with Russell's bodies lack mobility and phagocytic nature entirely. No function has been known for these cells. Rod or filamentous mitochondria scatter in the peripheral region of the cell body with a parallel orientation to the longitudinal axis of the cells.

In the peritoneal cavity of newts, a large number of histiocytes, leucocytes, lymphocytes, and mast cells were observed in addition to elements with Rus. sell's bodies. Cells with Russell's bodies existed at a frequency of 40 to 55 per cent in the free cell population. Histiocytes showed 40 to 50 per cent, but neutrophilic or eosinophilic leucocytes, lymphocytes and mast cells were found at very low frequency. Histiocytes are characterized by a kindney 
shaped nucleus: they are spherical just after preparation, but with time they become flat in form lying along the glass surface (Figs. 18-20). Histiocytes contain many mitochondria and refractive granules. They change their form slowly and are phagocytic in nature. Leucocytes and lymphocytes showed a more remarkable change in form than histiocytes.

2. Experiments to induce cell division. In spite of detailed observation, Ohuye (1936) failed to observe mitotic figure in free cells occurring in the

Table 1. The results of daily abdominal punctures without or with hypotonic solution, showing an increase in number of mitotic figure in cells with Russell's bodies, histiocytes, leucocytes, and large lymphocytes in the coelomic fluid of newts. For detail, see text.

\begin{tabular}{|c|c|c|c|c|c|c|c|c|c|c|c|c|c|c|c|c|}
\hline \multicolumn{17}{|c|}{ Laboratory stock newts } \\
\hline Day & 1 & 2 & 3 & 4 & 5 & 6 & 7 & 8 & 9 & 10 & 11 & 12 & 13 & 14 & 15 & $\mathrm{~T}$ \\
\hline $\begin{array}{l}\text { A specimen } \\
\text { Number of } \\
\text { dividing cell }\end{array}$ & 0 & 0 & 0 & 0 & 0 & 0 & 0 & 2 & 0 & 0 & 1 & 2 & 9 & 7 & 1 & 22 \\
\hline $\begin{array}{l}\text { B specimen } \\
\text { Number of } \\
\text { dividing cell }\end{array}$ & 0 & 0 & 0 & 1 & 0 & 2 & 0 & 2 & 3 & 6 & 7 & 2 & 5 & 7 & 2 & 37 \\
\hline $\begin{array}{l}\text { C specimen } \\
\text { Number of } \\
\text { dividing cell }\end{array}$ & 0 & 0 & 0 & 0 & 0 & 0 & 0 & 0 & 1 & 6 & 6 & 9 & 19 & 10 & 6 & 57 \\
\hline $\begin{array}{l}\text { D specimen } \\
\text { Nnmber of } \\
\text { dividing cell }\end{array}$ & 0 & 0 & 0 & 0 & 0 & 6 & 0 & 1 & 7 & 15 & 23 & 11 & 14 & 13 & 11 & 101 \\
\hline \multicolumn{17}{|c|}{ Kobe wild newts } \\
\hline Day & 1 & 2 & 3 & 4 & 5 & 6 & 7 & 8 & 9 & 10 & 11 & 12 & 13 & 14 & 15 & T. \\
\hline $\begin{array}{l}\text { A specimen } \\
\text { Number of } \\
\text { dividing cell }\end{array}$ & 1 & 1 & 1 & 4 & 1 & 6 & 3 & 5 & 6 & 19 & 7 & 8 & 9 & 25 & 30 & 126 \\
\hline $\begin{array}{l}\text { B specimen } \\
\text { Number of } \\
\text { dividing cell }\end{array}$ & 1 & 0 & 0 & 3 & 2 & 3 & 1 & 4 & 10 & 13 & 6 & 10 & 9 & 71 & 61 & 194 \\
\hline $\begin{array}{l}\text { C specimen } \\
\text { Number of } \\
\text { dividing cell }\end{array}$ & 0 & 2 & 9 & 4 & 0 & 10 & 15 & 20 & 7 & 7 & 7 & 6 & 9 & 6 & 22 & 124 \\
\hline $\begin{array}{l}\text { D specimen } \\
\text { Number of } \\
\text { dividing cell }\end{array}$ & 3 & 2 & 0 & 2 & 3 & 3 & 2 & 4 & 19 & 11 & 8 & 8 & 32 & 22 & 69 & 188 \\
\hline
\end{tabular}

coelomic cavity of newts. In the laboratory stock animals under study there was generally found no mitosis in the free cells. However, some experimental procedures as described below made it possible to induce mitotic division in the following four kinds of cells : elements with Russell's bodies, histiocytes, leucocytes, and large lymphocytes. Simple experiments to induce mitosis undertaken with the stock newts were carried on as follows (Table 1): In A specimen, about $0.05 \mathrm{ml}$ of peritoneal fluid was removed by peritoneal 

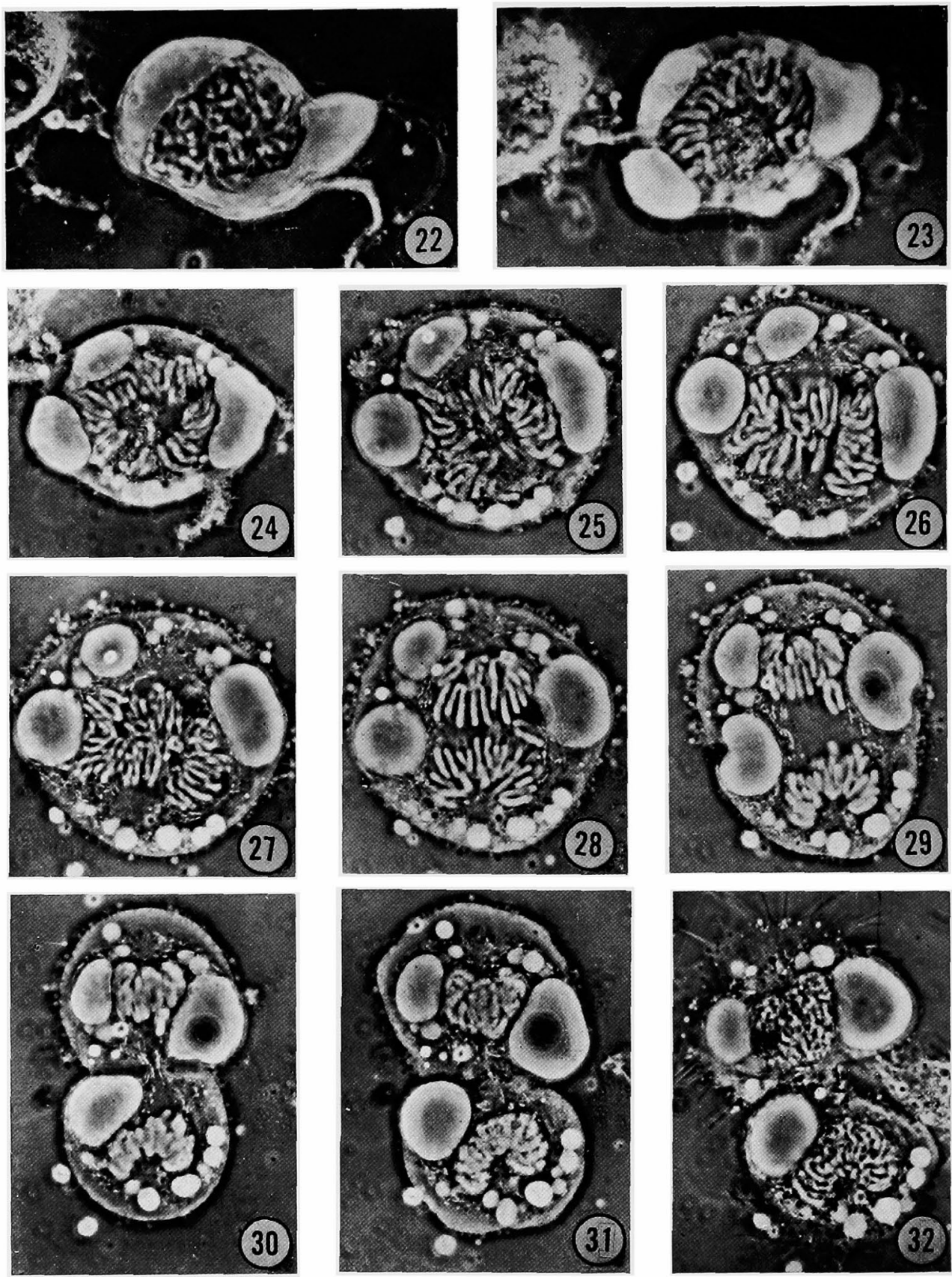

Figs. 22-32. Photomicrographs of the successive series of a division process in a free cell with Russell's bodies (Type 3), taken with a phase-contrast microscope. $\times 900$. 22 , prometaphase. The chromosomes were already distinct. Bipolar protoplasmic process is going to contraction. 23, early metaphase, showing the migration of chromosomes to the equatorial plate. 24, mid-metaphase. The chromosomes are arranged in the equatorial plate. The bipolar protoplasmic process is shown by numerous protrusions around the cell body. 25 , mid-metaphase, showing a splitting of chromosomes. 26, late-metaphase. The axis of spindle body lies parallel to slide. 27, early anaphase. 28, late anaphase. Daughter chro- 
puncture at first. From then on, about $0.005 \mathrm{ml}$ of coelomic fluid was removed once a day for fourteen days. In the specimen thus treated, mitotic figures were observed in the coelomic free cells. In B specimen, following the removal of about $0.05 \mathrm{ml}$ of peritoneal fluid on the first day, $0.05 \mathrm{ml}$ of distilled water was injected into the peritoneal cavity in order to accelerate the cellular reaction. In this specimen, mitotic figures were checked for fourteen days. In $\mathrm{C}$ specimen, approximately $0.005 \mathrm{ml}$ of coelomic fluid was simply taken out every day for fifteen days. In $\mathrm{D}$ specimen, after the removal of about $0.005 \mathrm{ml}$ of peritoneal fluid on the first day, about $0.005 \mathrm{ml}$ of distilled water was inoculated into its peritoneal cavity. The procedure was repeated for five days and then the same treatment for $\mathrm{C}$ was performed. In these specimens, dividing figures were observed in free cells occurring in their coelomic cavities.

The data summarized in Table 1 indicate that the number of dividing cells increases in the later period observed, and further that the number of dividing cells is larger in hypotonic treated animals than in non-treated animals.

A similar experiment was done with newts from Kobe in order to obtain information on mitosis. The results here obtained (Table 1) indicate similarity between the laboratory stock animals and the Kobe newts, but that cell division was more readily induced in the Kobe animals than in the stock animals. So far as the above two experiments are concerned, the induction of mitosis in the free cells in the coelomic fluid seems to be closely related firstly to a physical stimulus on the peritoneum, secondly to the decrease in number of the free cells, and thirdly to injected distilled water. The results of the following described experiments seem to supplement the above view. The cessation of daily peritoneal punctures induced a gradual decrease of the daily mitotic frequency. The injection of horse serum or saline into the peritoneal cavity of newts from the laboratory stock failed to induce cell division on the 1st, 3rd and 7th day after treatment.

3. The course of cell division. The successive stages of mitotic division from prophase to telophase were followed in a single cell with Russell's bodies (Figs. 22-32) and in some of other types with the aid of phase optics. In a cell with Russell's bodies, the chromosomes appeared as fine thread-like bodies in the nucleus. Then, swelling and expansion of the nucleus followed. In the meanwhile, the chromosomes took the appearance of long threads. They became thicker and shorter with time. Soon, the nuclear membrane became invisible and chromosomes which had been completed in their final form began to move toward the equatorial plate (Fig. 22) and radially oriented

mosomes reached to opposite poles. 29, early telophase, showing an elongation of cell body. Cleavage furrow begins to appear. 30, mid-telophase. 31, late telophase. The completion of cell division. 32, daughter nuclei showing a reconstruction. Bipolar protoplasmic process begins to appear again. 
leaving a clear center (Fig. 23). On the other hand, the bipolar protoplasmic process began to contract; several fine processes which developed from the main process were withdrawn into small round protrusions. At the same time filamentous process became shorter and shorter (Figs. 23 and 24). Either in the bipolar type or in the other one, a similar change was observed. In the meanwhile, a distinct splitting of each chromosomes became visible (Fig. 25), In this condition, the cell lost its characteristic form and became spherical. Then, the spindle axis turned to lie in parallel to the surface of the cover-slip (Fig. 26). Many minute granules like mitochondria were seen around the centrosomes, and also those of rod and filamentous form were found surrounding the zone of granular mitochondrial bodies (Figs. 23-26). The division of the chromosomes took place at anaphase, and the daughter chromosomes moved to the opposite poles after separation (Figs. 27-28). After the chromosomes reached the poles, the cell body elongated and then a cleavage furrow appeared across the middle part of the cell body (Fig. 26). Next, the daughter chromosomes lost their characteristic outline in the daughter nuclei reconstructed at telophase (Figs. 30-32). Cytoplasmic bodies were distributed unequally in the daughter cells (Figs. 31-32). In all stages through late-metaphase and anaphase, small protoplasmic protrusions which originated from bipolar processes were observed in the periphery of the cell (Figs. 2529). They show a remarkable oscillation during cell division. When the division of the cell was completed, the bipolor protoplasmic processes appeared in the pole-side stretching in opposite directions (Fig. 32).

The number of chromosomes was counted in cells at metaphase and found to be 24 in accordance with the reports of Iriki (1932) and Sato (1932).

In histiocytes, leucocytes, and large lymphocytes respectively, the course of cell division was followed; it was found that the course of division in them proceeded in a similar way to that described above.

\section{Discussion}

According to Ohuye (1936) who studied the morphological and cytochemical nature of cells native to the coelomic fluid of newts, the cells with Russell's bodies were those which had transformed from plasma cells originated from erythroblasts or granuloblasts. Maixmow and Bloom (1957) have stated that plasma cells are specially differentiated elements which finally degenerate, and that during the degeneration, large spherical drops or crystals of acidophilic nature frequently accumulate in the cell body. In the present phase optic observations with free cells occurring in the peritoneal fluid of newts, there was found no transitional form from any certain original cell to an element with Russell's bodies. Cells with Russell's bodies were conveniently arranged from immature (or young) type cells to mature (or old) type cells, based on a degenerative change of the cytoplasmic inclusions, though the arrangement is only a tentative one. 
In the normal coelomic fluid of newts, cells with Russell's bodies were found to exist at the frequency of 40 to 55 per cent in the free cell population. No dividing cells with Russell's bodies were found under the normal condition, but cell division could be induced rather easily by serial punctures of the peritoneum. No elements which correspond to cells with Russell's bodies were observed in the peritoneal fluid of Hynobius retardatus and Rana temperaria.

According to Iriki (1932) and Sato (1932), the chromosome number of newts, Triturus pyrrhogaster, is 24 in diploid. The present authors have observed also 24 diploid chromosomes in cells with Russell's bodies without variation. This strongly suggests that cells with Russell's bodies are not parasitic protozoa at all.

Felix and Dalton (1955) have studied the morphology of free cells occurring in the peritoneal fluid of mice; they have shown that cellular reaction to such stimuli as sodium chloride, melanin granules, or carbon particles, primarily involves neutrophilic granulocytes, macrophages and lymphocytes. They also found macrophages in mitosis in control mice, as well as under any of the conditions of stimulation, such as repeated daily punctures of the peritoneum, with an increase as high as 1 per cent. Kano (1953) has shown that the mitotic activity of monocytes native to the peritoneal fluid of rats is increased considerably by the injection of saline or glucose solution. In the coelomic fluid of newts, the cellular reaction to water and to repeated daily stimuli to the peritoneum was shown by a remarkable increase in the number of leucocytes and lymphocytes. At the same time, mitotic activity was induced in the cells with Russell's bodies, histiocytes, leucocytes and large lymphocytes. Evidently, there is a similarity between newts and mice or rats regarding the nature of free cells native to their peritoneal fluid. At present, nothing is known about the function of cells with Russell's bodies. Further, the mechanism for the induction of cell division in such cells is left for future study.

\section{Summary}

The present paper deals with a morphological and cytological study of free cells native to the coelomic cavity of newts, Triturus pyrrhogaster, by phase-contrast microscopy.

The coelomic free cell population of newts consists of cells with Russell's bodies $(40-55 \%)$, histiocytes $(40-50 \%)$, leucocytes, lymphocytes, and mast cells. Cells with Russell's bodies are characterized by bipolar protoplasmic process and cytoplasmic inclusions. They were roughly classified into four types according to the shape of the cytoplasmic inclusions.

There was no mitotic figure in cells with Russell's bodies in the normal coelomic fluid of newts. Cell division of free cells was induced through repeated daily abdominal punctures. There was a decrease of free cells 
with an increase of mitotic frequency following the stimuli in combination with the injection of hypotonic solution.

The successive stages of mitosis were followed serially in cells with Russell's bodies, and in three other kinds of free cells. Cells with Russell's bodies showed 24 chromosomes in both sexes.

\section{Literature}

Boolootian, R. A. and Giese, A. C. 1958. Coelomic corpuscles of echinoderms. Biol. Bull. 115: 53-63.

Felix, M. D. and Dalton, A. J. 1955. A phase-contrast microscope study of free cells native to the peritoneal fluid of DBA/2 mice. J. Nat. Cancer Inst. 16: 415-445.

Iriki, S. 1932. Studies on amphibian chromosomes. 6. On the chromosomes of Diemyctylus pyrrhogaster. Sci. Reports Tokyo Bunrikadaigaku, Sec. B, 1: 81-89.

Jones, J. C. 1956. The haemocytes of Sarcophaga bullata Parker. J. Morph. 99: 233-257.

Kano, K. 1953. Mitotic features of monocytes occurring in the peritoneal fluid of rats. J. Fac. Sci. Hokkaido Univ. Ser. 6, Zool. 11: 495-501.

Makino, S. 1957. The chromosome cytology of the ascites trmor of rats, with special reference to the concept of the stemline cells. Intern. Rev. Cytol. 6: 25-83.

- and Nakahara, H. 1953. Cytological studies of tumors. X. Further observation on the living tumor cells with a new hanging-drop method. Cytologia 18: 128-132.

- and - 1955. Study of cell division by phase microscopy. J. Hered. 46: 245-251.

Maximow, A. and Bloom, W. 1957. A textbook of histology, 7th ed. W. B. Saunders Co., Philadelphia and London.

Mizutani, M. 1958. A phase microscopy study of blood cells in the grasshopper, Podisma sapporense. (In Japanese). La Kromosomo 34-36: 1162-1166.

Ohuye, T. 1936. On the cells with Russell bodies in the coelomic fluid of Triturus pyrrhogaster (BOIE). (In Japanese). Zool. Mag. (Japan) 48: 545-551.

Rizki, M. T. M. 1953. The larval blood cells of Drosophila willistoni. J. Exp. Zool. 123: 397-411.

- 1957. Alternation in the haemocyte population of Drosophila melanogaster. J. Morph. 100: $437-495$.

Sato, I. 1932. Chromosome behavior in the spermatogenesis of urodele amphibia, Diemyetylus pyrrhogaster (BOIE) J. Sci. Hiroshima Univ. Ser. B, 2: 33-47. 